Tópico de Interesse Geral

\title{
Síndrome do Cabrito Mole ("Floppy Kid") ${ }^{1}$
}

\author{
Franklin Riet-Correa², Ivon Macedo Tabosa², Jackson Suelio de Vasconcelos ${ }^{2}$ e \\ Josemar Marinho de Medeiros²
}

\begin{abstract}
Riet-Correa F., Tabosa I.M., Vasconcelos J.S. \& Medeiros J.M. 2004. [Floppy Kid Syndrome.] Síndrome do Cabrito Mole ("Floppy Kid"). Pesquisa Veterinária Brasileira 24(2):111113. Centro de Saúde e Tecnologia Rural, Universidade Federal de Campina Grande, Campus de Patos, 58700-000 Patos, PB. E-mail: riet@ cstr.ufcg.edu.br

The Floppy Kid Syndrome is an acute disease of unknown cause, which affects 3 to 10 day-old kids. It is characterized by severe depression, flacid paralysis, dilatation of the abdomen and metabolic acidosis, without dehydration (paradoxical acidosis). The disease was decribed for the first time in the United States in 1987 and later in Canada and several countries in Europe (Tremblay et al. 1991, Meier 2002). This paper has the objective to show the characteristics of the disease, which al ready has been diagnosed in Paraíba and occurs probably in other states of Brazil, so that veterinarians and research workers could recognize it and give informations, which may clarify its etiology and pathogenic aspects. Additionally, the epidemiology, clinical signs and pathology of four outbreaks of floppy kid syndrome in Paraiba are reported.
\end{abstract}

INDEX TERMS: “Cabrito Mole”, Floppy Kid, goats, acidosis.

RESUM 0.- A síndrome do cabrito mole (Floppy Kid) é uma doença aguda, de causa desconhecida que afeta cabritos com 3 a 10 dias de idade. Caracteriza-se clinicamente por depressão profunda, paralisia flácida, dilatação do abdome e acidose metabólica, sem desidratação (acidose paradoxal). Foi descrita pela primeira vez nos EUA em 1987 e, posteriormente, no Canadá e diversos países da Europa (Tremblay et al. 1991, Meier 2002). Este trabalho tem o objetivo de divulgar as características da doença, que já foi diagnosticada na Paraíba, e provavelmente ocorra em outras regiões do Brasil, para que os veterinários e pesquisadores possam reconhecê-la e fornecer informações para contribuir ao esclarecimento dos aspectos etiológicos e patogênicos da mesma. Adicionalmente, são descritos a epidemiologia, os sinais clínicos e a patologia de quatro surtos da síndrome do cabrito mole em Paraíba.

TERMOS DE INDEXAÇÃO: Cabrito Mole, "Floppy Kid", caprinos, acidose.

\footnotetext{
${ }^{1}$ Recebido em 11 de novembro de 2003.

Aceito para publicação em 25 de novembro de 2003.

${ }^{2}$ Centro de Saúde e Tecnologia Rural, Universidade Federal de Campina Grande, Campus de Patos, 58700-000 Patos, PB. E-mail: riet@ cstr.ufcg.edu.br
}

\section{Epidemiologia}

A síndrome do cabrito mole afeta cabritos criados em confinamento ou em semiconfinamento, de 3 a 10 dias de idade. Ocasionalmente podem ser afetados cabritos de até 14 dias. Não se conhece a causa da doença, mas tem sido associada ao consumo excessivo de leite. Ocorre em filhos de cabras que produzem boa quantidade de leite e que por estarem confinadas, dão de mamar repetidamente aos seus cabritos. Em filhos de cabras que estão em pastagens, a doença não ocorre, aparentemente por que em condições extensivas as cabras dão de mamar com menor freqüência. Ocorre, também, em cabritos alimentados artificialmente, com leite pasteurizado ou sem pasteurizar. Em geral afeta os maiores e melhores cabritos. Ocorre em diversas raças, mas em algumas regiões dos EUA a doença tornou-se mais freqüente após a introdução da raça Bôer. No entanto, esse fato pode ser somente devido a que os produtores passaram a prestar mais atenção a seus animais, após a introdução de reprodutores de alto valor zootécnico, melhorando os níveis de alimentação e algumas práticas de manejo. A doença pode ser mais freqüente no final da época de parição. É provável que seja uma enterotoxemia causada por uma toxina bacteriana, produzida provavelmente por Escherichia coli ou alguma espécie 
de Clostridium, ou uma infecção por Cryptosporidium ou herpesvírus caprino. Em outros países a morbidade pode variar de 10 a 50\%e a letalidade de 30 a 50\% Morbidade de até $100 \%$ tem sido observada. Em alguns rebanhos ocorre a síndrome do cabrito mole e posteriormente, quando a estação de parição está mais adiantada, ocorrem casos de diarréia e pneumonia (Tremblay et al. 1991, Méier 2000).

\section{Sinais clínicos}

Cabritos normais e saudáveis aparecem subitamente com anorexia, extrema debilidade, incoordenação e paresia, seguida de paralisia flácida que afeta os quatro membros. Os animais deixam de mamar mas conseguem deglutir. Permanecem deitados com marcada depressão, não conseguem se manter em pé ou o fazem com dificuldade e apresentam abdome dilatado, atonia intestinal e os membros frios. Finalmente entram em coma. A morte ocorre após um curso clínico de 24 a 36 horas. É característica a ocorrência de acidose paradoxal (acidose sem desidratação). Pode haver hipotermia (aprox. 50\%dos casos), temperatura normal e, em alguns casos, hipertermia ( $10 \%$ dos casos). Na patologia clínica há uma acidose metabólica, com pH de 6,88 a 7,32 (normal: 7,41-7,44), diminuição dos níveis séricos de bicarbonato, cloro normal ou aumentado, cálcio ocasionalmente aumentado e potássio normal ou baixo. 0 lactato e as cetonas não estão aumentados. Não se observam sinais de diarréia, pneumonia, onfaloflebite, poliartrite ou outras doenças infecciosas (M eier P. 2002, Mary Smith 2003, Cornell University, comunicação pessoal).

\section{Patologia}

Nas necropsias, a lesão mais importante é uma marcada dilatação do abomaso que está repleto de leite coagulada com acentuado odor ácido. A mucosa deste órgão pode apresentar hemorragias petequiais difusas. Em casos de cabritos alimentados forçadamente, há presença de leite no rume e/ ou pneumonia por falsa via. As fezes no reto apresentam-se sólidas e duras (Meier 2002). Menciona-se a ocorrência de abscessos, poliartrite ou outras infecções como complicação da enfermidade, mas devemos levar em consideração que na Paraíba, e provavelmente em outros Estados, essas infecções neonatais são muito freqüentes. Não há lesões histológicas de significação, mas é necessário realizar necropsias e exames histológicos para tentar determinar a causa da doença.

\section{Diagnóstico}

O diagnóstico deve ser baseado nos sinais clínicos característicos, nos dados epidemiológicos e na resposta ao tratamento. Cabritos com a síndrome do cabrito mole não apresentam nenhum sinal de outras doenças. É importante determinar o grau de acidose e do desequilíbrio eletrolítico, assim como o valor globular (hematócrito) para constatar a ausência de desidratação. Deve ser realizado diagnóstico diferencial com colibacilose, doença do músculo branco, timpanismo abomasal, enterotoxemia por Clostridium perfringens tipos B ou $C$, pneumonias, onfaloflebites, poliartrites e hipotermia. A colibacilose septicêmica é mais freqüente em cabritos de menos de 3 dias e geralmente está associada à falhas na ingestão de colostro. Devem ser realizadas culturas de sangue ou vísceras para o isolamento de E. coli. As clostridioses mencionadas anteriormente, não têm sido descritas no Brasil, afetam principalmente caprinos na primeira semana de vida e causam enterite e diarréia hemorrágicas. A hipotermia é freqüente em cabritos que nascem com pouco peso e ocorre nos três primeiros dias de vida, principalmente no primeiro. A doença do músculo branco tem sido diagnosticada, na Paraíba, em caprinos adultos em confinamento, mas não em neonatos; devem ser realizados exames histológicos dos músculos esquelético e cardíaco para descartar a forma congênita desta enfermidade.

\section{Tratamento}

Os casos iniciais devem ser tratados oralmente com bicarbonato de sódio. Para isso, colocamos uma colher de chá rasa de bicarbonato $(4,5 \mathrm{~g})$ em um copo de água morna e administramos 10-20 ml a cada 2-3 horas. Inicialmente, pode ser administrada meia colher de chá de bicarbonato. Casos mais severos devem ser tratados por via intravenosa com uma solução de 1,3\% de bicarbonato de sódio. Devem administrar-se 125-200 ml num período de 1-3 horas. A recuperação é muito rápida após a administração intravenosa. Para evitar infecções secundárias recomenda-se administrar antibióticos ou quimioterápicos, por via oral, por 3-5 dias (Méier 2002, Mary Smith 2003, Cornell University, comunicação pessoal). Pelo baixo custo, recomenda-se meio comprimido diário de $50 \mathrm{mg}$ de enrofloxacina (Quinolon, Baytril, Flotril) ou meio comprimido com $15 \mathrm{mg}$ de sulfametoxazol e $3 \mathrm{mg}$ de trimetropim (Trissulfin, Sulfaprim, Bactrim). Pode ser tratado ainda com sulfaquinoxalina (Coccifim ou semelhante), $5 \mathrm{ml}$ de uma solução a $10 \%$ em água. Esses antibióticos ou quimioterápicos devem ser aplicados diariamente, durante 3-5 dias. Para a avaliação de qualquer tratamento devemos considerar que em alguns casos há recuperação espontânea.

É necessário suspender a administração e leite por um período de 24-36 horas. Após o tratamento os animais recuperam-se rapidamente, em algumas horas, mas podem ocorrer recidivas e alguns casos podem permanecer 4 a 6 semanas para recuperar-se totalmente.

\section{A doença na Paraíba}

Na Paraíba suspeita-se da ocorrência da doença desde 1999. Recentemente foram observados quatro surtos de mortalidade em cabritos com sinais clínicos característicos da síndrome do cabrito mole (Vasconcelos 2003). No primeiro surto um cabrito proveniente do município de Santa Terezinha foi trazido ao Hospital Veterinário apresentando sinais clínicos característicos. Foi tratado com florfenicol injetável, uma dose no primeiro dia e outra no terceiro, e com uma solução de bicarbonato de sódio, uma colher de chá em $200 \mathrm{ml}$ de água, via oral, $20 \mathrm{ml}$ na primeira administração e $10 \mathrm{ml}$ nas seguintes, com intervalo de 2-3 h, até completar $60 \mathrm{ml}$. Em 24 horas o cabrito reiniciou a tomar leite e às 72 horas foi devolvido ao produtor. Na fazenda havia 70 cabras. Nos últimos 35 dias haviam nascido $12 \mathrm{ca}$ britos, dos quais morreram 5 com sinais clínicos caracterís- 
ticos da síndrome do cabrito mole. Os cabritos tinham entre 5 e 8 dias de idade e estavam saudáveis antes de serem afetados. Todos morreram entre 24 e 36 horas. As cabras estavam a campo, em uma área de 25 ha, mas quando estavam próximo de parir, eram trazidas para uma área de $8 \mathrm{ha}$, ao lado da residência, onde há um aprisco.

Outro surto ocorreu em Patos num rebanho de 20 cabras, das quais quatro estavam paridas. De um total de oito cabritos, seis com 8 a 12 dias de idade foram afetados. Um dos animais apresentou diarréia. Todos os animais foram tratados mediante a administração oral de bicarbonato de sódio, da mesma forma que no caso anterior, e enrofloxacina por via oral. Foi recomendada a suspensão de ingestão de leite por 24 horas. Cinco cabritos se recuperaram em 12-24 horas e 0 restante às 48 horas. 0 proprietário relatou que no ano passado de 12 animais nascidos, quatro apresentaram a mesma sintomatologia e que em anos anteriores 0 problema sempre aparecia.

0 terceiro surto ocorreu em São Mamede, em um rebanho de aproximadamente 700 caprinos, com 100 cabritos lactantes de diferentes idades. Oito cabritos, com 5-15 dias de idade, apresentaram sinais clínicos característicos. Três animais morreram sem tratamento. Dos demais que foram tratados como no surto anterior, um morreu e os restantes se recuperaram.

Num quarto surto, no município de Santa Terezinha, foram afetad os quatro cabritos de 5 a 15 dias de idade. Dois morreram sem tratamento. Os dois restantes foram tratados: um morreu e o outro se recuperou após o tratamento.

Os sinais clínicos caracterizaram-se por aparecimento súbito de depressão e anorexia. Os sinais progrediam rapidamente até os cabritos permanecerem em decúbito esternal com paralisia flácida, com marcada flacidez do corpo e aumento de volume do abdome que se apresentava, também, flácido.

Em três necropsias realizadas, a única lesão observada foi marcada dilatação do abomaso, que estava repleto de leite e apresentava hemorragias petequiais difusas na mucosa. Não foram encontradas lesões histológicas de significação.

0 diagnóstico foi feito pelos dados epidemiológicos, sinais clínicos e lesões características e pela resposta ao tratamento.

\section{REFERÊNCIAS}

Meier P. 2002. http://home.att.net/ watersounds/floppy_kid_syndrome_articles.htm

Tremblay R.M., Butler D.G., Allen J.W. \& Hoffman A.M. 1991. Metabolic acidosis without dehydration in seven goat kids. Can Vet J. 32:308-310.

Vasconcelos]. S. 2003. Relatório. Estágio Supervisionado Obrigatório, Curso de Medicina Veterinária, Centro de Saúde e Tecnologia Rural, Universidade Federal de Campina Grande, p.13-16. 